\title{
Fuzzy Reliability Optimization for 2-Hub Center Problem with Cluster-Based Policy and Application in Cross-Border Supply Chain Network Design Using TS Algorithm
}

\author{
Chenyi Yan $\mathbb{D}^{1},{ }^{1}$ Xifu Wang $\mathbb{D}^{1},{ }^{1}$ and Kai Yang $\mathbb{D}^{1,2}$ \\ ${ }^{1}$ School of Traffic and Transportation, Beijing Jiaotong University, Beijing 100044, China \\ ${ }^{2}$ State Key Laboratory of Rail Traffic Control and Safety, Beijing Jiaotong University, Beijing 100044, China \\ Correspondence should be addressed to Kai Yang; kaiyang@bjtu.edu.cn
}

Received 13 November 2019; Revised 14 March 2020; Accepted 30 March 2020; Published 30 April 2020

Academic Editor: Zhile Yang

Copyright (c) 2020 Chenyi Yan et al. This is an open access article distributed under the Creative Commons Attribution License, which permits unrestricted use, distribution, and reproduction in any medium, provided the original work is properly cited.

As information and communication technology evolves and expands, business and markets are linked to form a complex international network, thus generating plenty of cross-border trading activities in the supply chain network. Through the observations from a typical cross-border supply chain network, this paper introduces the fuzzy reliability-oriented 2-hub center problem with cluster-based policy, which is a special case of the well-studied hub location problem (HLP). This problem differs from the classical HLP in the sense that (i) the hub-and-spoke (H\&S) network is grouped into two clusters in advance based on their cross-border geographic features, and (ii) a fuzzy reliability optimization approach based on the possibility measure is developed. The proposed problem is first modeled through a mixed-integer nonlinear programming (MINLP) formulation that maximizes the reliability of the entire cross-border supply chain network. Then, some linearization techniques are implemented to derive a linear model, which can be efficiently solved by exact algorithms run by CPLEX for only small instances. To counteract the difficulty for solving the proposed problem in realistic-sized instances, a tabu search (TS) algorithm with two types of move operators (called "Swap I" and "Swap II") is further developed. Finally, a series of numerical experiments based on the Turkish network and randomly generated large-scale datasets are set up to verify the applicability of the proposed model as well as the superiority of the TS algorithm compared to the CPLEX.

\section{Introduction}

Nowadays, under the environment of fierce market competition and economic globalization, enterprises have begun to focus on business improvement and management of complex supply chains. The enterprises are beginning to chase lower material/rental costs and seek new markets in other supply chain regions. And then, cross-border trading activities occur when products in one place have lower costs than in another. As a result, this type of corporate behavior between different countries and regions produces a crossborder supply chain. Generally, the cross-border supply chain is defined as the logistics flow of goods across international borders between separate geographical locations within a supply chain context. More specifically, in a crossborder supply chain, the raw materials/semifinished goods offered by various suppliers are first collected at a warehouse temporarily. The warehouse then delivers the goods to the cross-border inspection. After passing through the crossborder inspection (product examination, delivery document validation, etc.), the manufacturing plants/end-customers ultimately receive the goods. In reality, there are some typical cross-border supply chains in the world, such as (i) US-Mexico [1], (ii) Indonesia-Malaysia-Singapore [2], and (iii) Hong Kong-China Pearl River Delta region [3]. Aiming at the cross-border supply chain problem in Hong Kong, Leung et al. [4] proposed an optimization model, which can effectively find an optimal transportation strategy in terms of optimal delivery routes and optimal fleet composition. Subsequently, Leung et al. [5] presented a preemptive goal programming model for the multiobjective cross-border supply chain problem, in which three objectives are 
optimized hierarchically. D. P. Claro and P. Claro [6] formulated two possible models for building long-term B2B relationships to coordinate cross-border supply chains in the case of the organic coffee industry. Haytko et al. [7] gave suggestions for improving the situation facing in the maquiladora industry in Mexico and the cross-border supply chain in the future. Lam et al. [8] provided a decision support system (DSS) to enhance the performance of the cross-border supply chain, the goal of which is to improve order planning and fulfill customer orders within the warehouse. Wang et al. [9] investigated Zongteng, which is one of the first cross-border e-commerce companies in China, to assess how supply chain innovation activities can become core to a firm's business model innovation. To assess the direct and indirect cross-border supply chain models, Wong et al. [10] established a performance measurement system (PMS) framework, which covers four categories including cost, time, quality, and flexibility.

The design of the cross-border supply chain networks is one crucial component of the planning activities for the enterprises. Based on the above explanation of a crossborder supply chain, the cross-border supply chain network and the hub-and-spoke (H\&S) network are very similar. In practical terms, the raw material/semifinished goods suppliers (or manufacturing plants/end-customers) and warehouse (or cross-border inspection) in the cross-border supply chain network can be interpreted as demand nodes and hubs, respectively. Based on this, the cross-border supply chain network design problem can be considered as a 2-hub center problem which is a special case of the wellstudied hub location problems (HLPs). Following seminal works of O'Kelly $[11,12]$, the HLP has been well studied in the literature [13-21]. Detailed surveys that review early and recent works on the HLP classification, modeling, and solution methodologies can be found in Alumur and Kara [22], Campbell and O'Kelly [23], and Rabbani et al. [24]. On the contrary, the traditional HLPs do not consider the realistic geographical feature, resulting in hubs usually located within most of the well-developed areas because of their concentrated demands [25]. However, the typical cross-border supply chain network is grouped into two clusters in advance based on their cross-border geographic features, and the warehouse and the cross-border inspection are then located in each cluster, resulting in providing better service for end-customers and eventually improving the overall performance of the cross-border supply chain networks. Furthermore, in the real world, the HLPs contain strategic (long-term) decisions (e.g., hub location and allocation); this implies that several parameters such as demands, costs, and time may change. Thus, it is necessary to consider the HLP in an uncertain environment. For example, Yang [26] presented a two-stage stochastic programming model for air freight HLP and flight route planning under uncertain demand. Contreras et al. [27] investigated the stochastic uncapacitated HLP in which uncertainty is associated with demands and transportation costs. Boukania et al. [28] developed a robust optimization model for the single allocation and multiple allocation HLP with uncertain parameters, mainly including fixed setup costs and capacity of each node to be a hub. Sim et al. [29] attempted to tackle the HLP problem with uncertain time and utilized a chanceconstrained formulation to model the minimum servicelevel requirement.

Previous studies neglect the reliability performance for the cross-border supply chain network design problem. In today's severely competitive markets, however, most customers are looking for enterprises that provide more reliable delivery services. In addition, the reliability parameters of a cross-border supply chain are often fuzzy/imprecise because of incomplete or nonobtainable information, and the probabilistic approach to the conventional reliability analysis is inadequate to account for such built-in uncertainties. For this purpose, the concept of fuzzy reliability has been introduced and formulated in the context of possibility theory [30]. Since the pioneering work of Cai et al. [30], the fuzzy reliability theory has attracted extensive attention and has been applied in engineering optimization problems. For example, Utkin [31] studied the fuzzy reliability of repairable systems in possibility context and developed a recursive algorithm to compute the fuzzy reliability of some typical repairable systems. Huang et al. [32] presented a model for posbist fault tree analysis (posbist FTA) of coherent systems, in which event failure behavior is characterized in the context of possibility measures. Liu et al. [33] considered the optimal design of preventive maintenance policy using the fuzzy reliability framework, where an artificial neural network was used for reliability prediction and evaluation.

By combining these aforementioned aspects, the primary research objective of this paper is to propose a fuzzy reliability-oriented 2-hub center problem with cluster-based policy to design the cross-border supply chain network within the framework of fuzzy reliability theory. This problem aims to maximize the reliability of the entire crossborder supply chain network by locating the warehouse and cross-border inspection and allocating the raw material/ semifinished goods suppliers and manufacturing plants/ end-customers that are served by the corresponding warehouse and cross-border inspection, respectively. The second research goal of this paper is to develop an efficient TS algorithm to solve the proposed model to obtain optimal/ near-optimal solutions.

This paper makes the following contributions. (1) A cluster-based policy is adopted to capture the real-world geographical features of the cross-border supply chain network. (2) A hybrid approach, combining the 2-hub location modeling method and fuzzy reliability-oriented optimization, is proposed to formulate the cross-border supply chain network design problem. (3) A TS algorithm is developed to obtain high-quality solutions in a short computational time, in which two types of move operators (called "Swap I" and "Swap II") are developed to enhance the exploitation ability. (4) A series of computational experiments based on the Turkish network data set and randomly generated large-scale datasets are conducted to illustrate the applicability of the proposed model as well as the superiority of the TS algorithm compared to the CPLEX.

The remainder of this paper is organized as follows. In Section 2, we describe a modeling framework and formulate 
a fuzzy reliability-oriented optimization model for the crossborder supply chain network design problem in detail. In Section 3, we design a TS algorithm to solve the proposed model. In Section 4, we carry out a series of numerical experiments and analyze the computational results to validate the applicability of the proposed model and the effectiveness of the designed algorithm. Finally, we give some conclusions and outline directions for further research in Section 5 .

\section{Problem Statement and Formulation}

In this section, we explain how the fuzzy reliability-oriented 2-hub center problem with cluster-based policy is used to design the cross-border supply chain network and its formulation in detail.

2.1. Problem Description. Through observations from a typical cross-border supply chain network, we partition it into two clusters based on their cross-border geographic features (see Figure 1). More explicitly, the warehouse temporarily stores the raw materials/semifinished goods offered by various suppliers. Once the demand from manufacturing plants/end-customers is received, the warehouse delivers the goods to the cross-border inspection. After passing through the cross-border inspection, the manufacturing plants/end-customers ultimately receive the goods. That is, the warehouse is a transshipment center to connect suppliers and cross-border inspection before goods are delivered to manufacturing plants/end-customers. In the cross-border inspection, the goods delivered across regional boundaries need to undergo cross-border inspection processes, including product examination and delivery document validation. As mentioned above, the cross-border supply chain network design problem can be interpreted as a 2-hub center problem with cluster-based policy.

But, in reality, due to legal restrictions and complicated inspection procedures in a cross-border supply chain, there may exist some barriers that cause the reliability inefficiencies, which may result in material shortages and delivery delays. Reducing the barrier effects of a cross-border supply chain, we consider the reliability-oriented objective for the cross-border supply chain network design problem. That is, the reliability objective is to maximize the network reliability of the cross-border supply chain. From the view of an application, the reliability it takes to deliver the goods to the end-customers can be interpreted as the service level. As a result, the reliability objective can be very useful in today's severely competitive markets and thus can contribute to the success of cross-border supply chains.

In general, there exist two main reliability theories: probability reliability and fuzzy reliability. The probability reliability theory contains the binary-state assumption and the probability assumption. That is, the probability reliability theory defines the systems as functioning or failed and characterizes the system behavior in the context of probability measure. However, in the case of the small size of samples, the probability assumption is no longer reasonable since the probability measure proceeds from the sample generality. In this way, the possibility measure should be employed to characterize the sample particularity. Therefore, the fuzzy reliability based on the possibility measure, also referred to as the posbist reliability theory, can be adopted to characterize the reliability-oriented objective for the crossborder supply chain network design problem.

For all of these reasons, this study addresses a special case of the HLPs, namely, the fuzzy reliability-oriented 2-hub center problem with cluster-based policy. This new problem aims to find the locations of the warehouse and cross-border inspection and the allocations of raw material/semifinished goods suppliers and manufacturing plants/end-customers to the corresponding warehouse and cross-border inspection to maximize the fuzzy reliability of the entire cross-border supply chain network.

2.2. Posbist Reliability Theory. For the completeness of this research, we shall briefly introduce some relevant concepts and results in posbist reliability theory in the following discussion.

In an attempt to give an alternative to probabilistic reliability theory, Cai et al. [30] developed the posbist reliability theory, which is based on the following two assumptions:

The possibility assumption: the system failure behavior is fully characterized in the context of possibility measure.

The binary-state assumption: the system demonstrates only two crisp states: fully functioning or completely failed. That is, at any time, the system is in one of the two states.

Definition 1 (see [30]). A fuzzy variable is a real-valued function defined on a possibility space $\left(U, \Phi, P_{\text {oss }}\right)$, where $U$ is the universe of discourse, $\Phi$ is the discrete topology on $U$ (that is, the power set or the class of all subsets of $U$ ), and the scale $P_{o s s}$, which is a mapping from $U$ to $[0,1]$, satisfies the following properties:

(i) $P_{\text {oss }}(\Theta)=0$ and $P_{\text {oss }}(U)=1$, where $\Theta$ denotes the empty set.

(ii) For any arbitrary collection of sets $A_{\alpha}$ of $\Phi$,

$$
P_{\text {oss }}\left(\cup_{\alpha} A_{\alpha}\right)=\sup _{\alpha} P_{\text {oss }}\left(A_{\alpha}\right) \text {. }
$$

Definition 2 (see [30]). The possibility distribution function of a fuzzy variable by $X$, denoted by $\pi_{X}$, is a mapping from $R$ (the set of real numbers) to the unit interval $[0,1]$ and is given by $\pi_{X}(x)=P_{\text {oss }}\{v: X(v)=x\}$ for all $x \in R$.

Definition 3 (see [30]). Given a possibility space $\left(U, \Phi, P_{\text {oss }}\right)$, the sets $A_{1}, A_{2}, \ldots, A_{n} \subset \Phi$ are said to be mutually unrelated if for any permutation of the set $\{1,2, \ldots, n\}$, denoted by $i_{1}, i_{2}, \ldots, i_{k}$ for $1 \leq k \leq n$, 


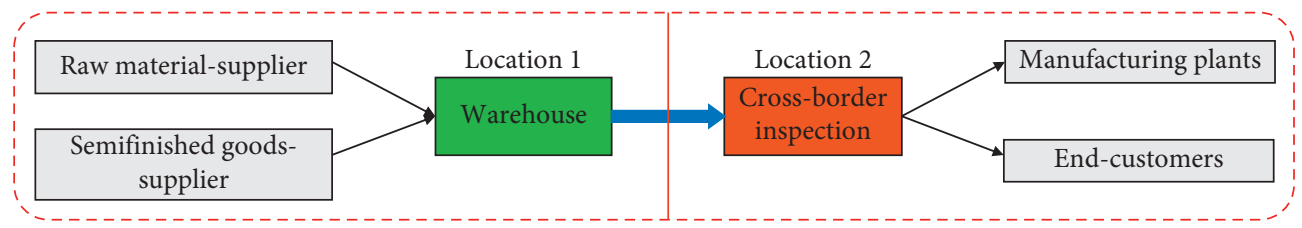

Figure 1: Cross-border supply chain.

$$
P_{\text {oss }}\left(A_{i_{1}} \cap A_{i_{2}} \cap \cdots \cap A_{i_{n}}\right)=\min \left(P_{\text {oss }}\left(A_{i_{1}}\right), P_{\text {oss }}\left(A_{i_{2}}\right), \ldots, P_{\text {oss }}\left(A_{i_{n}}\right)\right) .
$$

Definition 4 (see [30]). Given a possibility space $\left(U, \Phi, P_{\text {oss }}\right)$, the fuzzy variables $X_{1}, X_{2}, \ldots, X_{n}$ are said to be mutually unrelated if for any permutation of the set $\{1,2, \ldots, n\}$, denoted by $i_{1}, i_{2}, \ldots, i_{k}$ for $1 \leq k \leq n$, the sets

$$
\left\{X_{i_{1}}=x_{1}\right\},\left\{X_{i_{2}}=x_{2}\right\}, \ldots,\left\{X_{i_{k}}=x_{k}\right\}
$$

are unrelated for all $x_{1}, x_{2}, \ldots, x_{k} \in R$.

Formally, to assess the reliability of a cross-border supply chain network, we assume that the state of the network (system) is determined completely by the states of components (i.e., link and node), so the structure function of a system of $n$ components is denoted by

$$
\begin{aligned}
\phi & =\phi(X), \\
X & =\left(X_{1}, X_{2}, \ldots, X_{n}\right),
\end{aligned}
$$

where $X$ is the system state vector and $X_{i}$ represents the state of component $i$.

Assume that $X_{1}, X_{2}, \ldots, X_{n}$ and $\phi$ are all binary fuzzy variables defined on possibility space $\left(U, \Phi, P_{\text {oss }}\right)$ :

$$
\begin{aligned}
& X_{i}: U \longrightarrow\{0,1\}, \quad i=1,2, \ldots, n, \\
& \phi: U \longrightarrow\{0,1\} .
\end{aligned}
$$

Then, we assume

$$
\begin{aligned}
& X_{i}= \begin{cases}1, & \text { if the componentiis functioning, } \\
0, & \text { if the componentiis failed, }\end{cases} \\
& \phi= \begin{cases}1, & \text { if the system is functioning, } \\
0, & \text { if the system is failed. }\end{cases}
\end{aligned}
$$

According to aforementioned analysis, the posbist reliability of a cross-border supply chain network, denoted by $\mathrm{Re}$, is defined as

$$
\operatorname{Re}=P_{\text {oss }}(\Phi=1)
$$

2.3. Formulation of the Problem. To characterize the problem of interest, we first list all notations and decision variables used in the problem formulation, as shown in Table 1 and Table 2, respectively.

Remark 1. We remark that the relationship between link reliability and geographical distance can be calculated as $R_{i j}=F\left(D_{i j}\right)$, in which $R_{i j}$ is the reliability between nodes $i$ and $j ; D_{i j}$ is the distance, and $F(\cdot)$ is a step function based on the experiences and judgments of field experts. This sort of approach can give an effective and convincing way to qualitatively and quantitatively characterize the fuzzy reliability.

Given the network representation in Section 2, we can present the fuzzy reliability-oriented 2-hub center model with cluster-based policy for the cross-border supply chain network design problem as the following mixed-integer nonlinear programming (MINLP) formulation:

$$
\begin{aligned}
& {\left[\mathscr{P}_{0}\right] \max R e,} \\
& \text { s.t. } P_{o s s}\left\{R_{i k} \wedge \lambda R_{k l} \wedge R_{l j} \wedge r_{k} \wedge r_{l}\right\} \geq \operatorname{Re} * X_{i k} Y_{j l}, \quad \forall i, k \in N_{1}, j, l \in N_{2}, \\
& \sum_{k \in N_{1}} X_{i k}=1, \quad \forall i \in N_{1}, \\
& \sum_{l \in N_{2}} Y_{j l}=1, \quad \forall j \in N_{2}, \\
& X_{i k} \leq X_{k k}, \quad \forall i, k \in N_{1}, \\
& Y_{j l} \leq Y_{l l}, \quad \forall j, l \in N_{2}, \\
& X_{i k}, Y_{j l} \in\{0,1\}, \quad \forall i, k \in N_{1}, j, l \in N_{2} .
\end{aligned}
$$

Note that " $\wedge$ " means minimizing the arithmetic operator in the framework of the posbist reliability theory. Objective function (1) and constraints (2) are to maximize the fuzzy reliability of the entire cross-border supply chain network. In other words, it controls that the reliability from origin $i$ to destination $j$ via warehouse $k$ and cross-border inspection $l$ is not less than $\mathrm{Re}$, which means protecting the worst-case network reliability. Constraints (3) state that the raw material/semifinished goods supplier $i$ is assigned to precisely one warehouse. Constraints (4) ensure that the manufacturing plant/end-customer $j$ is assigned to precisely one cross-border inspection. Constraints (5) enforce that a raw material/semifinished goods supplier $i$ can only be assigned to an open warehouse $k$. Constraints (6) require that a manufacturing plant/end-customer $j$ can only be assigned to an open cross-border inspection $l$. Constraints (7) define the domain of all decision variables.

Theorem 1. Model $\left[\mathscr{P}_{0}\right]$ belongs to the single-assignment p-hub center problem and is NP-complete.

Proof. Model $\left[\mathscr{P}_{0}\right]$ can be interpreted as the single-assignment 2-hub center problem that maximizes the network performance in terms of reliability. Kara and Tansel [15] proved that the single allocation $p$-hub center location problem is NP-complete for $p<|N|-1$ by a reduction from the dominating set problem. Therefore, we might say that the model $\left[\mathscr{P}_{0}\right]$ is NP-complete. 
TABle 1: Notations in this problem.

\begin{tabular}{lc}
\hline Notations & Detailed definition \\
\hline$N$ & The set of nodes, $N=N_{1} \cup N_{2}$, i.e., two cross-boundary regions \\
$j$ & The raw material and semifinished goods supplier index, $i \in N_{1}$ \\
$j$ & The manufacturing plants and end-customer index, $j \in N_{2}$ \\
$l$ & The warehouse index, $k \in N_{1}$ \\
$R_{i k}$ & The cross-border inspection index, $l \in N_{2}$ \\
$R_{k l}$ & The fuzzy reliability from raw material/semifinished goods supplier $i$ to warehouses $k$ \\
$R_{l j}$ & The fuzzy reliability from warehouses $k$ to cross-border inspection $l$ \\
$r_{k}$ & The fuzzy reliability from cross-border inspection $l$ to manufacturing plant/end-customer $j$ \\
$r_{l}$ & The fuzzy reliability for warehouses $k$ \\
$\lambda$ & The fuzzy reliability for cross-border inspection $l$ \\
\hline
\end{tabular}

TABLE 2: Decision variables used in the formulation.

\begin{tabular}{lc}
\hline $\begin{array}{l}\text { Decision } \\
\text { variables }\end{array}$ & Detailed definition \\
\hline$X_{i k}$ & $\begin{array}{r}\text { Binary variable equals to } 1 \text { if raw material/semifinished goods supplier } i \text { is assigned to warehouses } k, \forall i, k \in N_{1} ; \\
\text { otherwise, equals to } 0 ; \text { note that } X_{k k} \text { equals to } 1 \text { if warehouses } k \text { is built, and } 0, \text { otherwise. }\end{array}$ \\
\hline$Y_{j l}$ & $\begin{array}{c}\text { Binary variable equals to } 1 \text { if manufacturing plant/end-customer } i \text { is assigned to cross-border inspection } l, \forall l, j \in N_{2} ; \\
\text { otherwise, equals to } 0 ; \text { note that } Y_{l l} \text { equals to } 1 \text { if cross-border inspection } l \text { is established, and } 0, \text { otherwise. }\end{array}$ \\
\hline
\end{tabular}

2.4. Linearization. It is well known that exact algorithms, e.g., branch-and-bound method, are useful tools to solve the combinatorial optimization problems for obtaining global optimal solutions. Furthermore, exact algorithms can be easily programmed and run by sophisticated standard mathematical programming software, e.g., CPLEX. However, the exact algorithm is the most suitable for solving the linear programming model. If the problem is formulated by a nonlinear programming model, the exact algorithm tends to be trapped in local optima. Moreover, the computation would consume a large amount of time, which significantly reduces the algorithm efficiency. Consequently, the linear reformulation of the model $\left[\mathscr{P}_{0}\right]$ should be derived.

Based on the linearization techniques, the constraints (2) can be replaced by their equivalent linear representations shown as

$$
\begin{aligned}
& P_{\text {oss }}\left\{R_{i k} \wedge \lambda R_{k l} \wedge R_{l j} \wedge r_{k} \wedge r_{l}\right\} \geq \operatorname{Re}-\left(1-Z_{i k l j}\right) * M, \quad \forall i, k \in N_{1}, j, l \in N_{2} \\
& Z_{i k l j} \geq X_{i k}+Y_{j l}-1, \quad \forall i, k \in N_{1}, j, l \in N_{2},
\end{aligned}
$$

in which $M$ is a large constant and $Z_{i k l j}$ represents the auxiliary binary decision variable, which equals to 1 if exists a route $i \longrightarrow k \longrightarrow l \longrightarrow j$ consisting of three arcs: $(i, k)$, $(k, l)$, and $(l, j)$; otherwise, equals to 0 .

The linearization for the model $\left[\mathscr{P}_{0}\right]$ now will be denoted by

$$
\begin{aligned}
& {\left[\mathscr{P}_{1}\right] \max \operatorname{Re},} \\
& \quad \text { s.t. constraints }(3)-(7),(9) .
\end{aligned}
$$

It is stated that the computational time increases drastically with the size of the cross-border supply chain network. Even for small-scale instances, the CPLEX solver is not effective to solve the proposed models, even the linearization (see Section 4 for more details). Based on the above discussion, optimally solving the model $\left[\mathscr{P}_{0}\right]$ for realistic-sized instances is very difficult. To counteract this difficulty, a TS algorithm is introduced to efficiently solve the model $\left[\mathscr{P}_{0}\right]$ in the next section.

\section{Tabu Search Algorithm}

TS is a well-known metaheuristic algorithm to find near-tooptimal solutions for combinatorial optimization problems [34]. The TS algorithm introduced by Glover [35] starts with an initial solution and employs a tabu list to control the moves in the neighborhood for avoiding local optimal. From the current solution, all the nontabu moves are explored, and the best one is chosen. The future move is among those not listed in the tabu list, unless it meets an aspiration criterion, i.e., it has a better objective value than the best-found objective.

Recall that the implementation of the TS algorithm is problem-dependent. To better fit our problem and enhance the method performance, we make twofold improvements for the TS algorithm: (i) designing a problem-based representation to keep the feasibility of solutions and (ii) developing two types of move operators to generate the neighbor. We believe that the proposed TS method is extensible and can potentially be employed for solving other classes of the 2-hub location problem too. The key procedures of the TS algorithm for solving the model $\left[\mathscr{P}_{0}\right]$ are described as follows.

3.1. Solution Representation. In the TS, the solution representation should contain the locations of the warehouse and cross-border inspection and the allocations of raw material/ semifinished goods suppliers and manufacturing plants/ end-customers to the corresponding warehouse and cross- 
border inspection. In this paper, we introduce an array with the length of $|N|=\left|N_{1}\right|+\left|N_{2}\right|$, in which $\left|N_{1}\right|$ and $\left|N_{2}\right|$ relate to the total number of nodes in two cross-boundary regions of the cross-border supply chain network (see Figure 2). In more specific terms, we first label the node numbers from left to right. Then, we further encode numbers in the array. These numbers denote the warehouse and cross-border inspection in the cross-border supply chain network to which the raw material/semifinished goods suppliers and manufacturing plants/end-customers are allocated. It is worth noting that the number in the array may be equal to the "column number." That is, the warehouse or crossborder inspection is allocated to itself. It is a highly effective representation scheme because it can always guarantee the feasibility of solutions.

3.2. Initial Solution Generation. To generate an initial solution, we first randomly select 1 out of $\left|N_{1}\right|$ nodes as a warehouse and 1 out of $\left|N_{2}\right|$ nodes as a cross-border inspection and then assign raw material/semifinished goods suppliers and manufacturing plants/end-customers to the selected the warehouse and the cross-border inspection. It is worth noting that this procedure can preserve initial solutions feasible.

3.3. Neighborhood Structures. For generating neighbors with a given current solution, we design two types of move operators in our TS algorithm. These two move operators, called "Swap I" and "Swap II," are used to alter the locations of the warehouse and cross-border inspection in the current solution, respectively. As shown in Figure 3, "Swap I" operator changes the location of a warehouse to a different (also randomly chosen) node in $N_{1}$, and "Swap II" changes the location of cross-border inspection to a different node in $N_{2}$. At each iteration of the neighborhood generation process, we choose one of the move operators to produce the next neighbor of the current solution. Specifically, the probability of choosing one of the move operators is initially set as 0.5 .

3.4. Tabu List. In this study, we choose the fixed approach based on our empirical tests which show the fixed list is efficient and resulted in no loss of solution quality. Specifically, $L_{\text {tabu }}$ denotes the size of the tabu list in this paper.

3.5. Aspiration Criterion. In this paper, we use the traditional aspiration criterion, i.e., if a move operator produces a better solution than the best-known solution and ensures that the generated solution is feasible, then the tabu status is disregarded, and the move operator is carried out.

3.6. Stopping Rule. In this research, we terminate the TS algorithm when the number of iterations reaches the maximum allowable number $I_{\max }$.

The computational flow of the TS algorithm is shown in Figure 4.

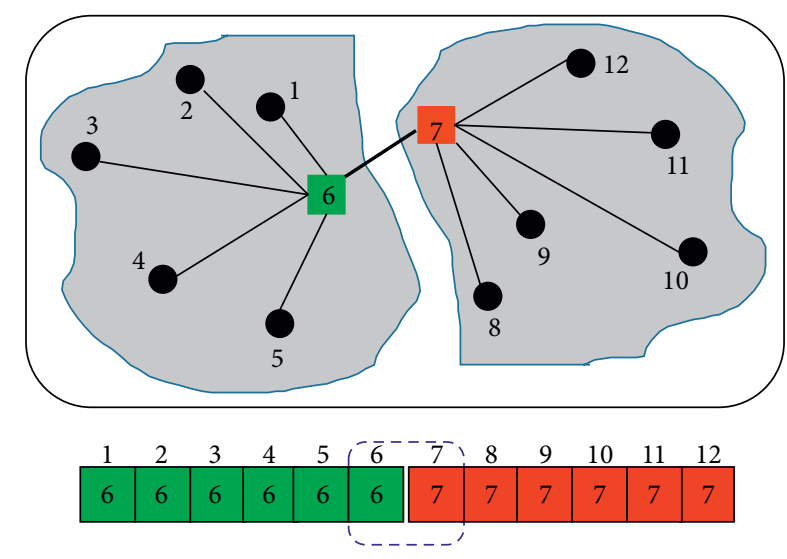

FIGURE 2: Solution representation.

\section{Numerical Experiments}

In this section, two sets of numerical experiments, involving the Turkish network and randomly generated large-scale datasets, are implemented to illustrate the proposed optimization model and test the effectiveness of the developed algorithm. The proposed TS algorithm is implemented in Microsoft Visual Studio C++ 6.0 software. All the numerical experiments have been run on a Lenovo computer with Intel(R) Core(TM) i7-6500U CPU @ $2.50 \mathrm{GHz}$ and RAM 8.0 GB using the Microsoft Windows 10 operating system.

As stated above, the TS requires one most important parameter, i.e., $L_{\text {tabu }}$, to be set to generate overall good results across most instances. Thus, we consider $L_{\text {tabu }}$ from the set $\{50,100,150,200\}$. After some experimentation, we find $L_{\text {tabu }}=50$ can produce the best results. Table 3 shows the convergence of TS with different sizes of the tabu list. The symbol "network reliability" represents the objective function value for the model $\left[\mathscr{P}_{0}\right]$, and the symbol "number of iterations" indicates the generation for the best solution. Note that the parameter has not changed the network reliability in the objective. It can be concluded that the TS heuristic algorithm is robust concerning the sizes of the tabu list. Finally, the max iteration $I_{\max }$ is set to 1,000 for the Turkish network and 2,000 for the randomly generated large-scale (RAND) data set in this study.

4.1. Turkish Network. In this section, we implement the numerical experiments on the Turkish network, which is a well-known data set in the HLP literature [36], because of shortages of data in the cross-border supply chain networks. Note that our model is a special case of the well-studied HLP. Consequently, the Turkish network data set can be used to test the proposed model, but it needs to be modified. The Turkish network contains 81 city nodes (e.g., $|N|=81$ ). For reflecting the cross-border geographic feature, we divide it into two groups, i.e., $N=N_{1} \cup N_{2}$, which are depicted in Figure 5. For the Turkish network, our experimental study is grouped into seven problem sizes $N \in\{10,15,20,25,30,50,81\}$. Table 4 presents the link reliability based on geographical distance [37]. Consider the fact that the link reliability across the international borders 


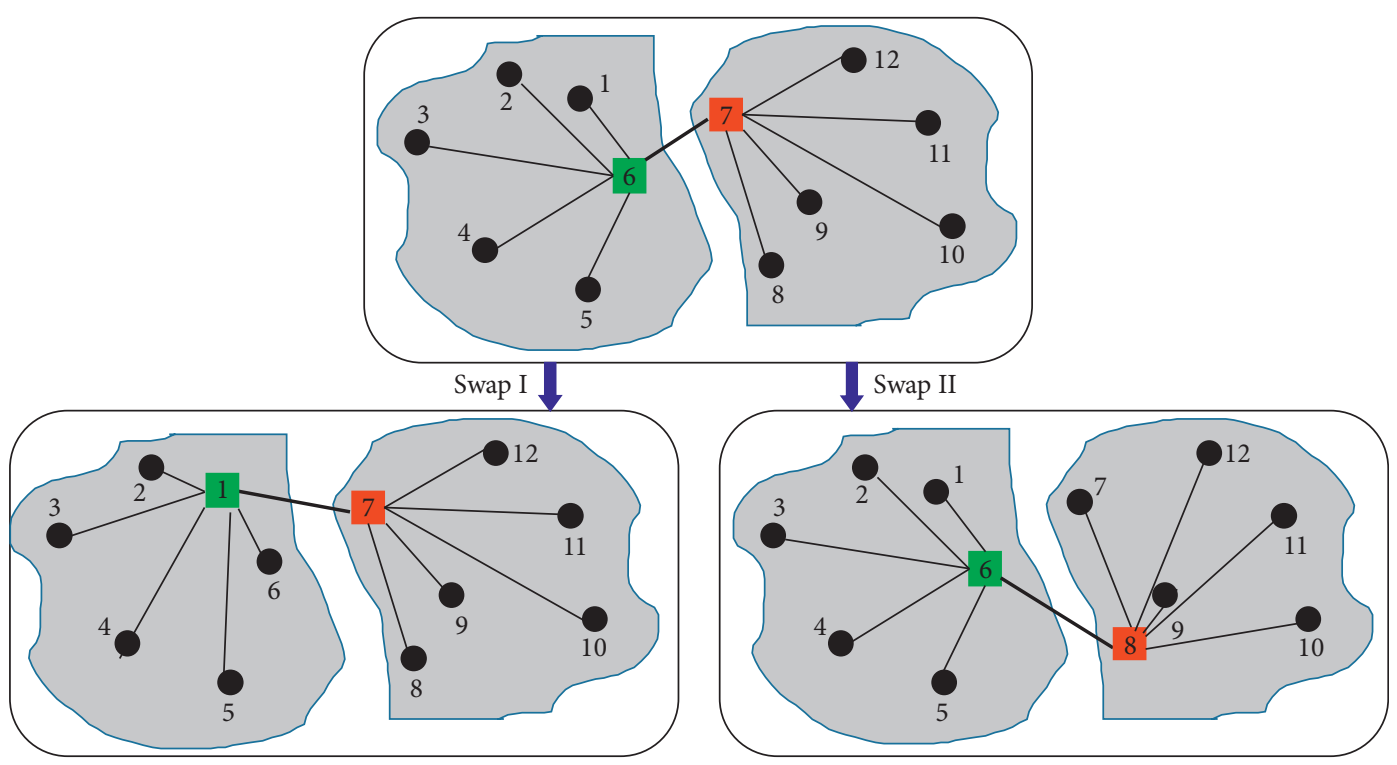

Figure 3: Neighborhood structures.

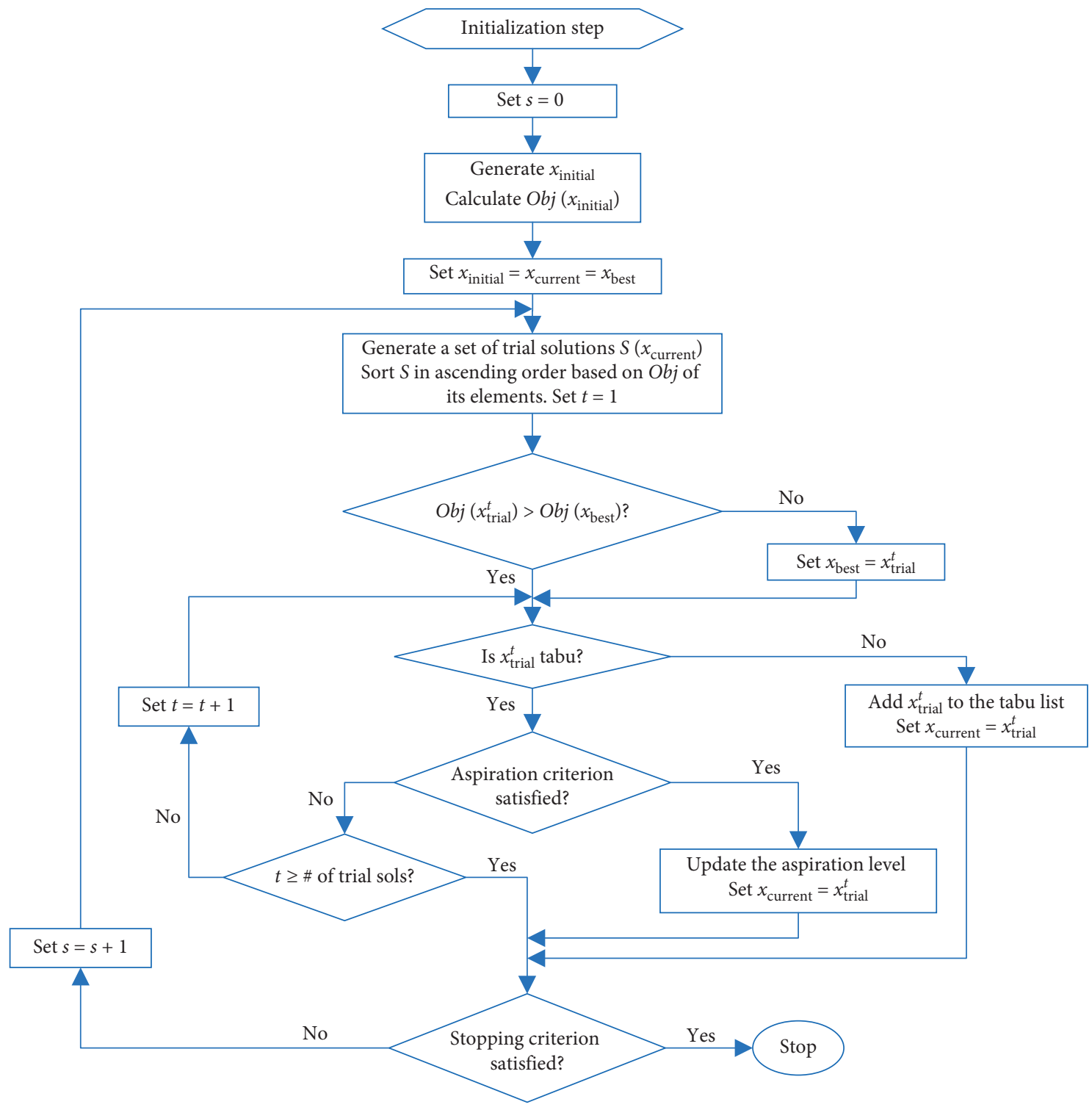

FIgURE 4: The computational flow of the TS algorithm. 
TABLE 3: The convergence of TS with different sizes of the tabu list.

\begin{tabular}{llr}
\hline$L_{\text {tabu }}$ & Network reliability & Number of iterations \\
\hline 50 & 0.840000 & 335 \\
100 & 0.840000 & 927 \\
150 & 0.840000 & 479 \\
200 & 0.840000 & 536 \\
\hline
\end{tabular}

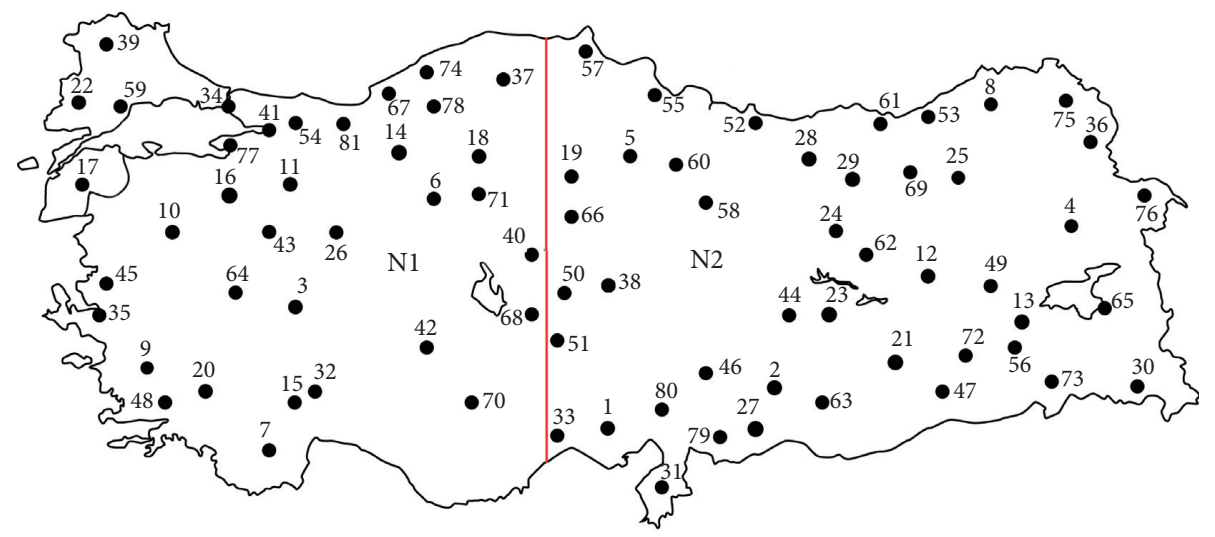

FIGURE 5: Turkish network.

TABLE 4: Link reliability based on geographical distance.

\begin{tabular}{lc}
\hline Distance between two city nodes $(\mathrm{Km})$ & Link reliability \\
\hline 0 & 1 \\
$(0-300]$ & 0.93 \\
$(300-350]$ & 0.92 \\
$(350-400]$ & 0.91 \\
$(400-450]$ & 0.90 \\
$(450-500]$ & 0.89 \\
$(500-600]$ & 0.88 \\
$(600-700]$ & 0.87 \\
$(700-800]$ & 0.86 \\
$(800-900]$ & 0.85 \\
$(900-1000]$ & 0.84 \\
$(1000-1100]$ & 0.82 \\
$(1100-1200]$ & 0.80 \\
$(1200-1400]$ & 0.78 \\
$(1400-1600]$ & 0.76 \\
$(1600-1800]$ & 0.74 \\
$(1800-\infty]$ & 0.72 \\
\hline
\end{tabular}

will be reduced, and we set the damping coefficient $\lambda \in\{0.8,0.9,1.0\}$. That is, the link reliability $R_{k l}$ is multiplied by $\lambda$. For the sake of convenience, the node reliability is set equal to 0.98 in the Turkish network.

To test the performance of our heuristic TS, we first solve a few 10-, 15-, 20-, 25-, and 30-node instances because CPLEX could not solve the larger-sized instances within limited computational time. We test the problem instances with $\lambda=1$. Table 5 presents the comparison results between CPLEX and TS for the Turkish network. Note from Table 5 that CPLEX solves all the instances on the model $\left[\mathscr{P}_{1}\right]$ optimally in an average of $1,534.49 \mathrm{~s}$. The maximum requirement of CPU time by CPLEX for the Turkish network with 30 nodes is about $5,725.95$ s. In addition, Table 5 shows that the performance of the linear model $\left[\mathscr{P}_{1}\right]$ is substantially better in CPU time than the model $\left[\mathscr{P}_{0}\right]$. It can also be observed from Table 5 that CPLEX cannot obtain feasible solutions for the model $\left[\mathscr{P}_{0}\right]$ on two instances with 25 and 30 nodes within 6 hours. Yet, our TS heuristic is able to find the optimal solution for all instances in an average of $11.57 \mathrm{~s}$. It can be observed from Table 5 that the TS outperforms the CPLEX solver in terms of the computational time. Besides, we provide the optimal network topology for the 10-, 15-, 20-, 25-, and 30-node instances in Figure 6.

We also test the TS on 50- and 81-node instances from the Turkish network data set. The summary of the computational results is listed in Table 6 . The columns entitled $|N|$ and $\lambda$ denote the size of the network and the damping coefficient for the reliability, respectively. It is observed from Table 6 that the multiplier factor $\lambda$ creates a big difference in the locations of warehouse and cross-border inspection. For example, in the 81-node instance, when $\lambda=0.8$, the optimal locations of warehouse and cross-border inspection are nodes 68 and 51. When $\lambda=1.0$, nodes 68 and 51 are changed to nodes 70 and 66 . Therefore, these obtained computational solutions can provide useful guidance to the enterprises for designing the more reliable cross-border supply chain networks.

To recognize the most significant parameters of the proposed model, sensitivity analysis is carried out, and the impact of parameter alteration on the objective function is investigated. It should be noted that all experiments are done for the 30-node problem, and all trends can be generalized for other sizes of the problem. Figure 7 illustrates the sensitivity of the objective function to the alteration of the 
TABle 5: Comparison results between CPLEX and TS for the Turkish network.

\begin{tabular}{|c|c|c|c|c|c|c|c|}
\hline \multirow[b]{2}{*}{$|N|$} & \multirow{2}{*}{$\begin{array}{c}\text { CPLEX } \\
\text { Network reliability }\end{array}$} & \multirow{2}{*}{$\begin{array}{c}{\left[\mathscr{P}_{0}\right]} \\
\mathrm{CPU}(\mathrm{s})\end{array}$} & \multirow{2}{*}{$\begin{array}{c}{\left[\mathscr{P}_{1}\right]} \\
\mathrm{CPU}(\mathrm{s})\end{array}$} & \multicolumn{4}{|c|}{ TS } \\
\hline & & & & $|N|$ & Network reliability & $\mathrm{CPU}(\mathrm{s})$ & Gap (\%) \\
\hline 10 & 0.86 & 58.2 & 1.81 & 10 & 0.86 & 0.094 & 0 \\
\hline 15 & 0.86 & 1292.14 & 40.81 & 15 & 0.86 & 0.49 & 0 \\
\hline 20 & 0.86 & 8622.2 & 395.94 & 20 & 0.86 & 9.89 & 0 \\
\hline 25 & 0.87 & - & 1507.92 & 25 & 0.87 & 20.09 & 0 \\
\hline 30 & 0.86 & - & 5725.95 & 30 & 0.86 & 27.30 & 0 \\
\hline Average & & & 1534.49 & & & 11.57 & \\
\hline
\end{tabular}

-: CPLEX cannot find a feasible within 6 hours.
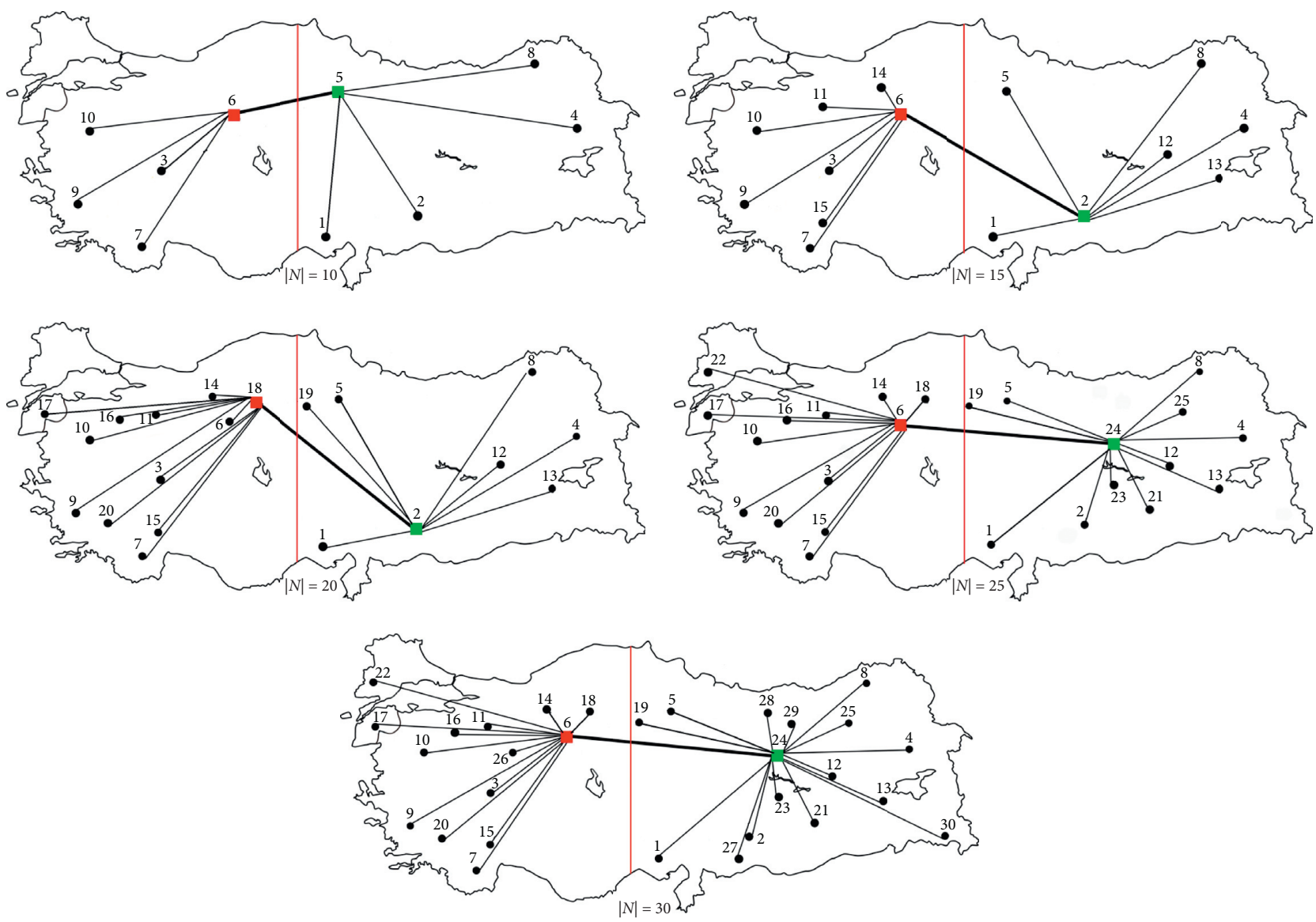

Figure 6: Optimal network topology.

TABLe 6: Computational results for the Turkish network with $|N|=50$ and $|N|=81$.

\begin{tabular}{cccccc}
\hline$|N|$ & $\lambda$ & Location of warehouses & Location of cross-border inspection & Network reliability & CPU (s) \\
\hline \multirow{3}{*}{50} & 0.8 & 40 & 50 & 0.744000 \\
& 0.9 & 40 & 19 & 0.828000 & 42.14 \\
& 1.0 & 18 & 38 & 0.840000 & 37.79 \\
\hline \multirow{3}{*}{81} & 0.8 & 68 & 51 & 0.744000 \\
& 0.9 & 68 & 19 & 0.820000 & 66.45 \\
\hline
\end{tabular}

damping coefficient $\lambda$. It can be seen that, as the damping coefficient $\lambda$ increases, the values of the objective function increase. This is an expected result because the link reliability between the warehouses and the cross-border inspection, as a key part of a cross-border supply chain network, has positive impacts on the network's overall reliability. In addition, Figure 8 illustrates the alteration of the objective function with respect to the node reliability. It can also be shown that, with an increase in the node reliability, the values of the objective function increase first and then 


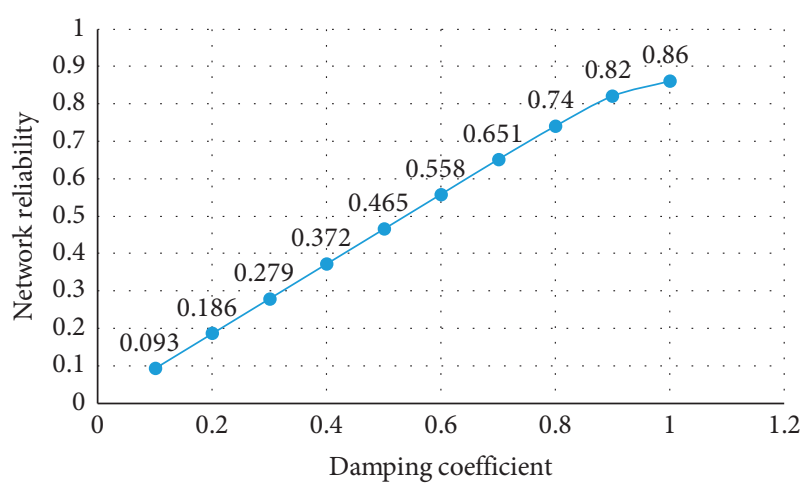

FIgURE 7: Network reliability vs. damping coefficient.

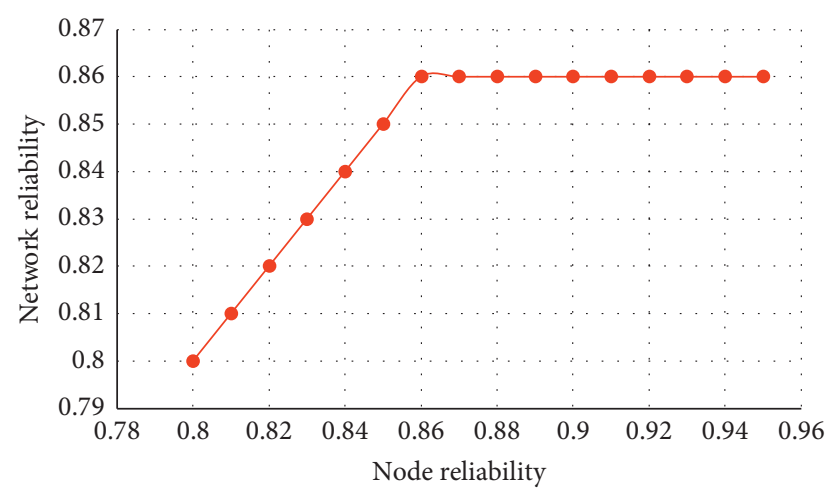

FIGURE 8: Network reliability vs. node reliability.

remain at a certain level. This indicates that the node reliability has the threshold response to the network reliability in the posbist reliability theory framework.

4.2. Large-Scale RAND Network. In this section, we conduct further computational experiments to study the performance of the proposed model on randomly generated largescale networks. With regard to this, three problem sizes are randomly generated: 100, 150, and 200 nodes. Then, we randomly generate the link reliability from the uniform distribution $[0.8,1]$. Particularly, we set the node reliability to 0.98 . We present the computational performance of the TS for the large-scale RAND network in Table 7. It can be seen from Table 7 that our heuristic TS algorithm can find good quality solutions in reasonable CPU time (average $292.54 \mathrm{~s}$ ) with its current structure.

\section{Conclusion and Future Research}

Nowadays, the reliable cross-border supply chain network design problem has significant impacts on the benefit of the enterprises. In this paper, we presented a fuzzy reliabilityoriented 2-hub center problem with cluster-based policy for designing a cross-border supply chain network. Firstly, we formulated a fuzzy reliability-oriented optimization so that the reliability of the network is maximized by locating the warehouse and cross-border inspection and allocating the raw material/semi-finished goods suppliers and
TABLE 7: Computational results for the large-scale URAND network.

\begin{tabular}{lccc}
\hline$|N|$ & $\lambda$ & Network reliability & CPU (s) \\
\hline \multirow{3}{*}{100} & 0.8 & 0.640405 & 113.19 \\
& 0.9 & 0.720456 & 144.64 \\
& 1.0 & 0.800134 & 115.68 \\
\hline \multirow{3}{*}{150} & 0.8 & 0.640195 & 208.40 \\
& 0.9 & 0.720220 & 212.71 \\
& 1.0 & 0.800079 & 234.95 \\
\hline \multirow{2}{*}{200} & 0.8 & 0.640103 & 509.33 \\
& 0.9 & 0.720115 & 535.48 \\
Average & 1.0 & 0.800031 & 558.45 \\
\hline
\end{tabular}

manufacturing plants/end-customers for delivering goods. Secondly, by using some linearization techniques, we reformulated the original MINLP as a linear model, which can be efficiently solved by the CPLEX for only small instances. Due to the computational complexity, we proposed an efficient TS algorithm to find optimal/near-optimal solutions for large-size instances within a reasonable time limit. Finally, we conducted a series of numerical experiments based on the Turkish network and randomly generated large-scale datasets to assess the performance of the proposed model and solution approach.

The present study tried to make the cross-border supply chain network design more realistic by considering the cross-border geographic feature and reliability factor, but many areas could be investigated to enrich this research. Firstly, we can integrate the operation problem model into the proposed strategic planning model and simultaneously consider the uncertain demand, cost, and travel time parameters. Secondly, we can develop a time-dependent fuzzy programming [38] model for the cross-border supply chain network design problem under uncertainty. Finally, we can consider other metaheuristic algorithms (e.g., the squirrel search algorithm [39] and the memetic algorithm [40]) to increase the performance of achievements in future research.

\section{Data Availability}

The Turkish network datasets used in our numerical experiments are from publicly available studies, which have been cited in our paper. The Turkish network datasets are provided at the web page https://ie.bilkent.edu.tr/ bkara/ dataset.php.

\section{Conflicts of Interest}

The authors declare that there are no conflicts of interest regarding the publication of this paper.

\section{Acknowledgments}

This work was supported in part by the National Natural Science Foundation of China (nos. 71701012, 71890972/ 71890970, 71621001, and 71631007), in part by the Fundamental Research Funds for the Central Universities (no. 2020JBM031), and in part by the State Key Laboratory of Rail 
Traffic Control and Safety (no. RCS2019K002), Beijing Jiaotong University.

\section{References}

[1] A. Hausman and D. L. Haytko, "Cross-border supply chain relationships: interpretive research of maquiladora realized strategies," Journal of Business \& Industrial Marketing, vol. 18, no. 6/7, pp. 545-563, 2003.

[2] J. Shen, "Cross-border connection between Hong Kong and mainland chain under "two systems" before and beyond 1997," Geografiska Annaler: Series B, Human Geography, vol. 85, pp. 1-17, 1997.

[3] C. Yang, "The Pearl River Delta and Hong Kong: an evolving cross-boundary region under "one country, two systems"” Habitat International, vol. 30, no. 1, pp. 61-86, 2006.

[4] S. C. H. Leung, Y. Wu, and K. K. Lai, "An optimization model for a cross-border logistics problem: a case in Hong Kong," Computers \& Industrial Engineering, vol. 43, no. 1-2, pp. 393-405, 2002.

[5] S. C. H. Leung, Y. Wu, and K. K. Lai, "Cross-border logistics with fleet management: a goal programming approach," Computers \& Industrial Engineering, vol. 50, no. 3, pp. 263272,2006

[6] D. P. Claro and P. Claro, "Coordinating B2B cross-border supply chains: the case of the organic coffee industry," Journal of Business \& Industrial Marketing, vol. 19, pp. 405-414, 2004.

[7] D. L. Haytko, J. L. Kent, and A. Hausman, "Mexican maquiladoras: helping or hurting the US/Mexico cross-border supply chain?" The International Journal of Logistics Management, vol. 18, no. 3, pp. 347-363, 2007.

[8] C. H. Y. Lam, K. L. Choy, and S. H. Chung, "A decision support system to facilitate warehouse order fulfillment in cross-border supply chain," Journal of Manufacturing Technology Management, vol. 22, no. 8, pp. 972-983, 2011.

[9] Y. Wang, F. Jia, T. Schoenherr, and Y. Gong, "Supply chainbased business model innovation: the case of a cross-border E-commerce company," Sustainability, vol. 10, no. 12, p. 4362, 2018.

[10] D. W. C. Wong, K. L. Choy, H. K. H. Chow, and C. Lin, "Assessing a cross-border logistics policy using a performance measurement system framework: the case of Hong Kong and the Pearl River Delta region," International Journal of Systems Science, vol. 45, no. 6, pp. 1306-1320, 2014.

[11] M. E. O’Kelly, "The location of interacting hub facilities," Transportation Science, vol. 20, pp. 92-106, 1986.

[12] M. E. O’Kelly, “A quadratic integer program for the location of interacting hub facilities," European Journal of Operational Research, vol. 32, pp. 393-404, 1987.

[13] J. F. Campbell, "Integer programming formulations of discrete hub location problems," European Journal of Operational Research, vol. 72, no. 2, pp. 387-405, 1994.

[14] D. Skorin-Kapov, J. Skorin-Kapov, and M. O’Kelly, “Tight linear programming relaxations of uncapacitated $p$-hub median problems," European Journal of Operational Research, vol. 94, no. 3, pp. 582-593, 1996.

[15] B. Y. Kara and B. Ç. Tansel, "On the single-assignment p-hub center problem," European Journal of Operational Research, vol. 125, no. 3, pp. 648-655, 2000.

[16] A. T. Ernst, H. Hamacher, H. Jiang, M. Krishnamoorthy, and G. Woeginger, "Uncapacitated single and multiple allocation p-hub center problems," Computers \& Operations Research, vol. 36, no. 7, pp. 2230-2241, 2009.
[17] A. Ilić, D. Ursević, J. Brimberg, and N. Mladenović, “A general variable neighborhood search for solving the uncapacitated single allocation $p$-hub median problem," European Journal of Operational Research, vol. 206, pp. 289-300, 2010.

[18] B. Yıldız and O. E. Karaşan, "Regenerator Location Problem and survivable extensions: a hub covering location perspective," Transportation Research Part B-Methodological, vol. 71, pp. 32-55, 2015.

[19] X. Sun, W. Dai, Y. Zhang, and S. Wandelt, "Finding p-hub median locations: an empirical study on problems and solution techniques," Journal of Advanced Transportation, vol. 2017, Article ID 9387302, 23 pages, 2017.

[20] W. Dai, J. Zhang, X. Sun, and S. Wandelt, "HUBBI: iterative network design for incomplete hub location problems," Computers \& Operations Research, vol. 104, pp. 394-414, 2019.

[21] H. Mokhtar, M. Krishnamoorthy, and A. T. Ernst, "The 2allocation p-hub median problem and a modified Benders decomposition method for solving hub location problems," Computers \& Operations Research, vol. 104, pp. 375-393, 2019.

[22] S. Alumur and B. Y. Kara, "Network hub location problems: the state of the art," European Journal of Operational Research, vol. 190, no. 1, pp. 1-21, 2008.

[23] J. F. Campbell and M. E. O'Kelly, “Twenty-five years of hub location research," Transportation Science, vol. 46, no. 2, pp. 153-169, 2012.

[24] M. Rabbani, M. Hekmatfar, A. B. Arabani, and E. Nikbakhsh, "Hub location problems: a review of models, classification, solution techniques, and applications," Computers \& Industrial Engineering, vol. 64, pp. 1096-1109, 2013.

[25] Y. Yuan and J. Yu, "Locating transit hubs in a multi-modal transportation network: a cluster-based optimization approach," Transportation Research Part E: Logistics and Transportation Review, vol. 114, pp. 85-103, 2018.

[26] T.-H. Yang, "A two-stage stochastic model for airline network design with uncertain demand," Transportmetrica, vol. 6, no. 3, pp. 187-213, 2010.

[27] I. Contreras, J.-F. Cordeau, and G. Laporte, "Stochastic uncapacitated hub location," European Journal of Operational Research, vol. 212, no. 3, pp. 518-528, 2011.

[28] F. H. Boukania, B. F. Moghaddam, and M. S. Pishvaee, "Robust optimization approach to capacitated single and multiple allocation hub location problem," Journal of Computational and Applied Mathematics, vol. 35, pp. 45-60, 2016.

[29] T. Sim, T. J. Lowe, and B. W. Thomas, “The stochastic $p$-hub center problem with service-level constraints," Computers \& Operations Research, vol. 36, no. 12, pp. 3166-3177, 2009.

[30] K. Y. Cai, C. Y. Wen, and M. L. Zhang, "Fuzzy variables as a basis for a theory of fuzzy reliability in the possibility context," Fuzzy Sets and Systems, vol. 42, pp. 145-172, 1991.

[31] L. V. Utkin, "Fuzzy reliability of repairable systems in the possibility context," Microelectronics Reliability, vol. 34, no. 12, pp. 1865-1876, 1994.

[32] H.-Z. Huang, X. Tong, and M. J. Zuo, "Posbist fault tree analysis of coherent systems," Reliability Engineering \& System Safety, vol. 84, no. 2, pp. 141-148, 2004.

[33] Y. Liu, Y. Li, H.-Z. Huang, M. J. Zuo, and Z. Sun, “Optimal preventive maintenance policy under fuzzy Bayesian reliability assessment environments," IIE Transactions, vol. 42, no. 10, pp. 734-745, 2010.

[34] K. Yang and Y. Liu, "Developing equilibrium optimization methods for hub location problems," Soft Computing, vol. 19, no. 8, pp. 2337-2353, 2015. 
[35] F. Glover, "Future paths for integer programming and links to artificial intelligence," Computers \& Operations Research, vol. 13, no. 5, pp. 533-549, 1986.

[36] B. Y. Kara, https://ie.bilkent.edu.tr/bkara/dataset.php.

[37] W. Zhang, X. Wang, and K. Yang, "Uncertain multi-objective optimization for the water-rail-road intermodal transport system with consideration of hub operation process using a memetic algorithm," Soft Computing, vol. 24, no. 5, pp. 3695-3709, 2020.

[38] Y. Sun, M. Hrušovský, C. Zhang, and M. Lang, "A timedependent fuzzy programming approach for the green multimodal routing problem with rail service capacity uncertainty and road traffic congestion," Complexity, vol. 2018, Article ID 8645793, 22 pages, 2018.

[39] T. Zheng and W. Luo, "An improved squirrel search algorithm for optimization," Complexity, vol. 2019, Article ID 6291968, 31 pages, 2019.

[40] R. Wang, K. Yang, L. Yang, and Z. Gao, "Modeling and optimization of a road-rail intermodal transport system under uncertain information," Engineering Applications of Artificial Intelligence, vol. 72, pp. 423-436, 2018. 